\title{
Airblast avoidance learning sets in rhesus monkeys*
}

\author{
GERALD R. STOFFER $\div$ and ROBERT R. ZIMM!ERMANN \\ Lniversity of Montana. Missoula. Uontana 59801
}

\begin{abstract}
Five rhesus monkeys were tested across a series of object discrimination problems requiring avoidance of noxious pressurized air. Each $\mathrm{S}$ displayed a progressive reduction in the number of trials to reach criterion on particular problems, eventually achieving $82 \%$ and $88 \%$ correct performance on Trials 2-6 and Trial 6 . respectively. Certain error factors also appearing in appetitive discrimination learning set research (stimulus perseveration and differential cue) were identified. as well as a factor of relative unimportance in appetitive set (positional responding). A most persistent appetitive error factor presumably reflecting a tendency to explore the unchosen object (response shift) did not appear. In addition. the results extend the effectiveness of aversive airblasts to a relatively complex discrimination task.
\end{abstract}

Harlow (1959) has indicated that learning set (LS) performance. in addition to other forms of discrimination learning, may be measured with reference to the appearance of certain error-producing factors. Although Harlow's analysis was derived from an investigation of appetitive LS. it presumably applies to aversive discrimination learning as well. An initial purpose of this experiment was to establish empirically the formation of an object-quality discrimination avoidance learning set and to identify the presence of any attendant systematic error tendencies.

It was earlier noted by Behar (1961) that avoidance processes may play a role in the development of the typical appetitive LS. He showed that discrimination sophisticated monkeys tend to aroid the stimulus associated with nonreward on a "critical" trial in which the prior nonrewarded stimulus was paired with a new (and also nonrewarded) stimulus.

It seems reasonable to expect in the analysis of avoidance LS the appearance of certain kinds of errors found in appetitive discrimination problems (Harlow. 1950). when the same kind of rule (i.e.. win-stay/lose-shift with respect to object) generates the problems. In this experiment. the animal was required to stay with an object selection that avoided a noxious stimulus and to shift from an object selection that failed to do so. As in appetitive LS. errors due to stimulus perseveration (an excess of consecutive errors following a first trial error beyond those expected from the obtained frequency of all errors) and to differential cue (a tendency to respond to the position previously rewarded although the correct object changes position) may occur. However, a third error factor. response shift. which presumably identifies a tendency for the animal to explore the incorrect stimulus (Harlow. 1950). would seem less likely to operate to produce errors when such variability in responding results in avoidance failures. Furthermore. it may be necessary to add a factor(s) not

*Thi, investigation Was supported in part by the Nutrition loundation. Inc.. Grant No. 401, and the Sational Institute of Child Health and Human Development. Grant No. ROI-HD-04863

-Requests for reprint, hould be ent to cierald Stoffer. Department of Pigholog!. Patific Lutheran Iniversit!. Tacoma. Washington $984+7$ operating in appetitive LS due to the increased motivation level extant with the use of noxious stimuli (positional responding, for example).

A secondary purpose of this experiment was to extend the effectiveness of aversive airblasts beyond the relatively simple behavioral tasks studied thus far, which have included shuttle avoidance (Polidora \& Boyer, 1967). Sidman avoidance (Rohles, 1964), Pavlovian aversive conditioning (Galambos \& Sheatz, 1962), and the conditioned emotional response (Kaplan \& Rebert. 1969).

\section{METHOD}

\section{Subjects}

The $S$ s were five male rhesus monkeys (Macaca mulatta) approximately 5 years (Ss 1. 4. 5) or 3 years (Ss 2 and 3 ) of age at the beginning of the experiment. Animals 1, 2, and 3 were obtained from the Oregon Primate Center at about 9 months of age and were subsequently maintained on Purina monkey chow: Their date of maternal separation is unknown. Animals 4 and 5 were born in the laboratory and separated from their mothers at 90 days of age. At 14 months of age. these Ss were introduced to a low-protein diet described previously by Geist. Zimmermann. and Strobel (1972). Rehabilitation to a diet containing relatively high quantities of protein had been in effect for approximately 20 months at the time of testing.

All Ss had participated in prior experiments using food rewards. including an appetitive discrimination LS for two of the Ss $(4$ and 5$)$.

\section{Apparatus}

The apparatus was a Wisconsin general test apparatus. consisting of a forward compartment in which problems were presented on a movable tray and a $24 \times 22 \times 24$ in. rear restraining chamber. The rear corners of the restraining chamber were eliminared by means of a wradual bend of the metal from the rear center to hatf of the distance forward on each side. thus ensuring a more nearly uniform distribution of air. Pressurized air was presented through three separate 'z-in. copper tubes clamped to the peripher! of the chamber. The tubes were positioned horizontally at heights of 2.12 . and 22 in.. axtendins from the forward portions of the chamber to intersect with a 3-in. copper tube positioned vertically at the rear middle of the chamber. Air was discribled to the tubes via the ofening of a normally closed solenojd blye attached in line with an ov!gen regulator and compressed air alinder. Air latt the copper tuber through 0.043 -in. openings along each tube and entered the chamber b! pasing through larger $1^{1}$-in.l holes sut in the 
Table 1

Trials and Problems to Criterion

\begin{tabular}{|c|c|c|c|c|c|}
\hline \multirow[b]{3}{*}{$S$} & \multicolumn{3}{|c|}{$\begin{array}{l}\text { Median Trials to Complete } \\
\text { the Intraproblem Criterion }\end{array}$} & \multirow{2}{*}{\multicolumn{2}{|c|}{$\begin{array}{c}\text { Problems and Trial } \\
\text { to Reach the } \\
\text { Interproblem } \\
\text { Criterion } \\
\end{array}$}} \\
\hline & \multirow{2}{*}{$\begin{array}{l}\text { First } \\
\text { Five } \\
\text { Problems }\end{array}$} & \multirow{2}{*}{$\begin{array}{l}\text { Middle } \\
\text { Five } \\
\text { Problems }\end{array}$} & \multirow{2}{*}{$\begin{array}{l}\text { Iast } \\
\text { Five } \\
\text { Problems }\end{array}$} & & \\
\hline & & & & $\begin{array}{c}\text { Total } \\
\text { Problems }\end{array}$ & $\begin{array}{l}\text { Total } \\
\text { Trials }\end{array}$ \\
\hline 1 & 58 & 22 & 20 & 34 & 1290 \\
\hline 2 & 146 & 28 & 23 & 44 & 2091 \\
\hline 3 & 79 & 25 & 22 & 51 & 1674 \\
\hline 4 & 43 & 23 & 21 & 15 & 586 \\
\hline 5 & 71 & 29 & 21 & 33 & 1249 \\
\hline
\end{tabular}

chamber walls. The bottom tube had 18 openings. each spaced by 3 in. Alternating with openings cut horizontal to the base of the chamber were other openings cut at 30 deg upward from the base. The top tube was identical to the bottom, except that every other opening angled $30 \mathrm{deg}$ downward from the base. The middle tube had 28 openings, spaced every 2 in., with openings altemating in a sequence of horizontal, $30 \mathrm{deg}$ upward, and 30 deg downward. Air pressure taken at gauges attached to the top of the rear vertical tube and to a forward corner of the top tube is as 20 psi. The blast duration was $0.5 \mathrm{sec}$.

Three silent Hunter timers were used to program tone duration. airblast presentation. and airblast duration. Initiation of each trial was accomplished by opening an opaque screen separating the two compartments. which also closed a microswitch leading to the timers. The circuit was broken by means of a foot reset switch.

Stimulus pairs land the designation of the correct object in each pair) were randomly assigned from a set of stereometric, laboratory fabricated objects to form the discrimination problems

\section{Procedure}

Pretesting consisted of training the animals to displace a single object in order to avoid a signaled airblast. Initial responding was developed by requiring each $S$ to displace a single object placed over a center foodwell baited with sugar-coated cereal 30 times within $10 \mathrm{~min}$. The conditioned stimulus (a $250-\mathrm{Hz} 78-\mathrm{dB}$ tone) alone was subsequently presented during 10 additional food trials. The signal and airblast contingency were then added to food reward in the second phase, with each $S$ required to respond to the tone prior to the completion of the interstimulus interial $(6 \mathrm{sec})$ over 25 consecutive trials. Finally, an identical criterion was attained under conditions of air avoidance alone.

Learning set problems were each learned to a criterion of 20 correct responses in 25 consecutive trials. instead of the more usual 6 trials/problem technique, in order that no animal would undergo the high frequency of airblasts (errors) that would inevitably attend the early performance on each of a series of problems given for only a few trials. The Ss were required to meet an interproblem criterion of 10 of 11 consecutive problems each learned to the intraproblem criterion within a maximum of 25 trials (Rumbaugh \& McQueeney. 1963). One problem and no more than 125 trials were given to a $S$ each day.

A trial began with tone presentation initiated by opening of the opaque screen. Following a brief pause, the stimulus tray supporting two objects was pushed within reach of $S$. By responding to the appropriate object within $6 \mathrm{sec}$ of tone onset, $\mathrm{S}$ terminated the tone, avoided the blast. and ended the trial. Inappropriate responses were followed by an immediate retraction of the tray. the completion of the ISI. and presentation of the blast (a noncorrection procedure). Failures to avoid due to balking initiated the immediate presentation of a nell trial. instead of the 16 -see intertrial interval that otherw ise followed responding. The position of the correct object was altered randomly across trials.

\section{RESULTS}

Each animal proceeded rapidly through the three pretraining requirements, taking no more than $20 \mathrm{~min}$ per requirement per $S$. The introduction of the tone alone resulted in no reliable change in either the form or latency of food responding. With the addition of airblasts received during the pretraining phases requiring avoidance, however, reception of the first one or two blasts was followed by extremely rapid and vigorous displacement of the object on the immediate and subsequent trials. Only one $\mathrm{S}$ gave any indication of balking in subsequent discrimination testing. and these responses were usually observed during the first trial of a discrimination problem. Each monkey developed an idiosyncratic and stereotyped fear response that remained specific to the experimental apparatus. There were only occasional difficulties in handling the animals during their exposure to the airblast treatment.

Intraproblem and interproblem discrimination performance is recorded over the first five, middle five. and last five problems in Table 1. There was a progressive decline in the mean (of the medians) number of trials required to solve individual problems $(\mathrm{F}=10.73, \mathrm{df}=1 / 4, \mathrm{p}<.05$, conservative test, Winer, 1971, pp. 205-210). Table 2 summarizes intraproblem performance over the same training blocks and clearly indicates substantial improvement in the mean percentage correct responses for both Trials 2-6 $(\mathrm{F}=5.50, \mathrm{df}=2 / 8, \mathrm{p}<.05)$ and Trial $6(\mathrm{~F}=5.45$, $\mathrm{df}=2 / 8, \mathrm{p}<.05$ ). Trial 2 performance. in contrast. improved nonsignificantly $(\mathrm{F}<1, \mathrm{df}=2 / 8, \mathrm{p}>.05)$. It is apparent from an examination of these tables that $\mathrm{Ss}$ were beginning to solve problems rapidly by the middle five problems but were unable to do so without committing several errors during the initial trials of these problems.

The nonsignificant Trial 2 performance appeared to be related to the relative inability to emit lose-shift behavior. The mean percentage correct Trial 2 responses, summed over total problems, was $67 \%$ subsequent to a correct Trial 1 response compared to $41 \%$ correct responding following an initial error $(t=4.23, \mathrm{df}=4$, $p<.01)$. The same effect was apparent with respect to meeting the interproblem criterion for particular problems. The mean percentage of problems solved within this criterion was $80 \%$ subsequent to a correct

Table 2

Percentage of Correct Responses Across Training

\begin{tabular}{lccc} 
Trial & $\begin{array}{c}\text { First Five } \\
\text { Problems }\end{array}$ & $\begin{array}{c}\text { Middle Five } \\
\text { Probiems }\end{array}$ & $\begin{array}{c}\text { Last Five } \\
\text { Problems }\end{array}$ \\
\hline 2 & 52 & 48 & 64 \\
$2-6$ & 51 & 54 & 82 \\
6 & 48 & 60 & 88 \\
\hline
\end{tabular}


initial response vs $48 \%$ after an incorrect Trial 1 response $(\mathrm{t}=6.92 . \mathrm{df}=4 . \mathrm{p}<.01)$.

\section{Error Factor Analysis}

Following the procedures of Harlow (1950), the frequencies of particular kinds of systematic errors were identified (from each animal's total problems to criterion) using the first six trials of each problem as a sample of responding. The most obvious error was that of positional responding, with four of the five Ss showing significant preference for one of the two positions (S 1: $\chi_{1}^{2}=3.84, \quad \mathrm{p}<.05 ; \quad \mathrm{S} 2: \chi_{1}^{2}=8.03$, $\mathrm{p}<.01 ; \quad \mathrm{S} 3: \quad \chi_{1}^{2}=4.72, \mathrm{p}<.05 ;$ S 5: $\chi_{1}^{2}=12.61$. $\mathrm{p}<.001)$.

Errors due to response shift were negligible. The number of errors on Trials 4,5 , or 6 following three. four, or five prior consecutive correct responses, respectively, totaled only 10 across all problems. There were an approximately equal number of errors observed for comparable Trials 4,5 , or 6 preceded by a Trial 1 error and correct responses during the two, three, or four intervening trials, respectively. Moreover, most of the responses counted as "response shift" errors were, upon closer examination, due to errors following a shift in the position of the correct object (differential cue).

There was a significantly $(t=2.61, \mathrm{df}=4, \mathrm{p}<.05)$ greater mean percentage errors on differential cue Trials 2 and 3 combined (42\%) than on comparable multiple cue trials $(21 \%)$. The total number of obtained stimulus perseveration errors (156) exceeded the total of those predicted (74) by more than $2: 1$.

\section{DISCUSSION}

Each S displayed a progressive improvement in solving problems as is characteristic in the formation of a learning set (Harlow. 1959), eventually achieving 82\% and $88 \%$ correct performance on Trials $2-6$ and Trial 6 , respectively.

The failure to achieve a high level of efficiency on Trial 2 was partly related to the relative inability of these animals to shift immediately to the correct object after an initial error, compared to the ability to repeat a correct trial response. The same effect was found considering the percentage of problems solved within the interproblem criterion. These particular results stand in contrast to the general finding in appetitive LS indicating superior performance on trials subsequent to an incorrect rather than a correct Trial 1 response (e.g., Harlow \& Hicks. 1957). Harlow and Hicks (1957) attributed this difference to a tendency of the animals to explore the unchosen object (response shift). which would result in more errors after choosing the correct than the incorrect object. The reversal of this relationship obtained in the present experiment suggests the absence of investigative errors in avoidance LS and is fully consistent with the unsuccessful attempt 10 identify a response shift error factor.
Rumbaugh and McQueeney (1963), training naive squirrel monkeys under criterion procedures identical to those used here. obtained on the last five problems a relatively higher percentage of correct Trial $2(80 \%)$. Trials $2-6(89 \%)$, and Trial $6(100 \%)$ responses rewarded with raisins. Their .our animals took an average of 19.5 problems and an average of 708 total trials to reach the interproblem criterion contrasted to 35.4 problems and 1,378 trials in the present study. These differences across reinforcement conditions seem especially large in view of the fact that the behavior of the two Ss with prior appetitive LS experience appeared to transfer somewhat positively to the avoidance LS (as evidenced by these Ss achieving the two lowest total problems and total trials to the interproblem criterion).

Errors appearing in the formation of an appetitive LS (stimulus perseveration and differential cue) were identified, in addition to those produced by positional responding, which is of negligible importance as an error factor in appetitive LS (Harlow, 1950). However. the most persistent error factor in appetitive IS (response shift) did not appear.

The present results also bear on other airblast research demonstrating particularly rapid acquisition of relatively simple Pavlovian (Galambos \& Sheatz. 1962) and instrumental avoidance responses (Ray \& Lenz, 1968). Both authors pointed out several advantages of airblast stimulation. including an apparent attenuation of the disruptive emotional responses concomitant with more severe aversive stimuli such as electric shock. Polidora and Boyer (1967) have supported this view by demonstrating more rapid acquisition of a shuttlebox response reinforced with avoidance of airblasts vs shock avoidance. In addition, the noise component of the blast alone was insufficient to maintain avoidance. Ray and Hranchuk (1967) obtained airblast avoidance in rats deprived of normal hearing. indicating further the operation of pressurized air as an independent aversive event.

This experiment demonstrates that rhesus monkeys can form learning sets to aversive reinforcement. The efficiency of learning set performance does not appear to be as good as appetitive learning set formation when these animals are compared to lower primates learning to the same criterion. Finally'. the error factors contributing to learning set are similar but not identical to those found in appetitive situations.

\section{REFERENCES}

Behar. I. Learned avoidance of nonreward. Psychological Reports. 1961. 9.43-52

Galambos. R.. \& Sheatz, G. C. An electroencephalograph study of classical conditioning. American Journal of Physiologs. 1962. 203. 173-184.

Geist. C. R. Zinmermann. R. R. \& Strobel. D. A. Eftect oi protein-calorie malnutrition on food consumption. Weight sain. serum proteins. and ativit! in the developing rlicus.

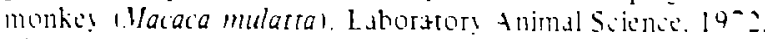
2.. 369.377 
Harlow. H. I. Analysis of discrimination learning by monkeys. Journal of Lxperimental Pirchology. 1950. 40. 26-39.

Harlow. H. F. Learning at and error fistor theory. In S. Koch (td.). Psichologn: At study of a science. Vol. 2. New York: Meiraw -Hill. 1959. Pf. 492-537.

Harlow. H. F. \& Hiks. L. H. Distrimination learning theory: Lniprocess is duoprociss. Psychological Review, 1957, 64. 104-109.

Kaplan. J.. \& Rebert. $G$. The eftect of pressurized air in establishing discriminative response suppression in stumptail macaques. Behasior Research Ifethods \& Instrumentation. 1969. 1. 262-263.

Polidora. V. G.. \& Boyer. II. N. Avoidance learning by squirrel monkeys: Neasures and motivators. Psychonomic Science. 1967.7.175-176.

Ray. A. J.. Jr.. \& Hranchuk. K. B. Pressurized air: The negative factor. Piychonomic Science. 1967. 9. 249-250.
Ras. A. J.. Jr.. \& Lenz. P. Pressurized air shuttle avoidanci and emotionality. Journal of Genetic Psychology. 1968. 112. 43-48.

Rohles. $\mathrm{l}$. H. Wind as an aversive stimulus. Journal of the Experimental Analysis of Behavior. 1964, 8, 203-205.

Rumbaugh. D. M.. \& McQueeney, J. A. Learning-set formation and discrimination reversal: Learning problems to criterion in the squirrel monkey. Journal of Comparative \& Physiological Psychology. 1963. 56, 435-439.

IViner. B. J. Statistical principles in experimental design. New York: MoCraw-Hill. 1971.

(Received for publication lebruary 1. 1973: revision received A pril 26. 1973.) 